\title{
Сорбционные и физико-химические характеристики целлюлозосодержащих сорбентов, модифицированных гетарилформазанами
}

\author{
Маслакова Т.И., Первова И.Г., Желновач А.В., Маслаков П.А., \\ Симонова Е.И., Вураско А.В.
}

Уральский государственньй лесотехнический университет, Екатеринбург

Поступила в редакцию 12.07.2016 г.

\begin{abstract}
Методом иммобилизации гетарилформазанов на целлюлозные матрицы-носители синтезированы новые сорбенты, применимые для концентрирования и экспресс-определения ионов меди(II) и ртути(II). Изучены закономерности адсорбции на целлюлозную матрицу формазановых реагентов, установлено влияние природы и количества заместителей в составе молекулы реагента на химикоаналитические характеристики получаемых тест-систем для оценки качества водных сред.

Ключевые слова: дифенилпиримидинил- и бензазолилформазаны, целлюлозосодержащая матрица, модифицированные сорбенты, адсорбция формазанов, сканирующая электронная микроско-
\end{abstract} пия.

\section{Sorption and physical and chemical properties of hetarylformazane-modified cellulose sorbents}

\author{
Maslakova T.I., Pervova I.G., Zhelnovach A.V., Maslakov P.A., \\ Simonova E.I., Vurasko A.V. \\ Ural State Forest Engineering University, Ekaterinburg
}

\begin{abstract}
Advanced sorbents are synthesized by immobilizing hetarylformazans on cellulose carrier matrices. The sorbents are applied for concentration and rapid determination of ions $\mathrm{Cu}(\mathrm{II})$ and $\mathrm{Pb}$ (II) in aqueous media.

While studying adsorption of formazans onto matrices obtained from rice husk and a composition of rice husk and oat straw, it was established that quantity of the fixed formazan groups increases in the series: benztiazolyl-<benzyl-benzimidazolyl-<diphenyl-pyrimidinylformazans. Presence of the acceptor carboxyl group in the formazan structure results to increasing both amine group (NH) acidity and quantity of matrixfixed formazan groups being in ionized state, and consequently, results to the spectral shift.

The report presents results of using of benzyl-benzimidazolyl-based sorbents for determining ions $\mathrm{Cu}(\mathrm{II})$ in aqueous media. Increasing colour intensity of the synthesized chelate is in proportion to concentration of ions $\mathrm{Cu}(\mathrm{II})$ in the range from 0.1 to $1.3 \mathrm{mg} / \mathrm{dm}^{3}$.

Keywords: formazane, hard-phase supporter, modified sorbents, formazan adsorption, scanning electronic microscopy
\end{abstract}

\section{Введение}

Целлюлозосодержащие материалы на основе возобновляемого сырья занимают видное место в удовлетворении потребностей человека, причем разнообразие областей применения их связано не только с доступностью и низкой стоимостью, но и с возможностью направленного изменения свойств за счет модифицирования 
функциональных групп полимера с применением доступных реагентов и простых технологических операций [1-4].

Особого внимания заслуживают высокоэффективные и сравнительно недорогие сорбенты на основе технической целлюлозы, полученной окислительноорганосольвентным способом из сельскохозяйственных отходов - шелухи и соломы риса и овса [5-7]. Состав такого носителя определяется природой и структурой волокон используемых растений. Так, большое количество аморфных областей целлюлозы из шелухи риса способствует легкому проникновению и удержанию жидкостей, что позволяет рассматривать ее как перспективный носитель-матрицу для полуколичественных визуальных тест-методов анализа, выполняемых без привлечения дорогостоящего оборудования и высококвалифицированных специалистов. Создание данных средств контроля в зависимости от поставленных задач включает поиск уникальных сочетаний органического реагента определенной структуры, матрицы и способа взаимодействия функционально-аналитических группировок реагента с аналитом [8-15].

В качестве хромофорных реагентов перспективно использование полидентатных гетарилформазанов, давно зарекомендовавших себя в качестве эффективных аналитических реагентов для определения содержания ионов металлов [16-18].

Однако при разработке экспрессных и чувствительных методик тест-анализа водных сред малоизученными остаются вопросы, касающиеся процессов адсорбции из растворов и изменений физико-химических свойств реагентов при их иммобилизации на целлюлозосодержащие матрицы. Установление же закономерностей адсорбции на целлюлозную матрицу формазановых реагентов и их комплексов с ионами металлов позволит вести направленный синтез тест-систем с наилучшими характеристиками.

Цель работы состояла в изучении особенностей адсорбции, химикоаналитических свойств бензазолил- и пиримидинилформазанов на целлюлозосодержащей матрице (ЦСМ) и применении новых тест-форм для концентрирования и экспресс-определения ионов меди(II) и ртути(II).

\section{Эксперимент}

Методика иммобилизации гетарилформазановых группировок на целлюлозосодержащий носитель. В коническую колбу емкостью $100 \mathrm{~cm}^{3}$, содержащую $20 \mathrm{~cm}^{3}$ раствора формазана с концентрацией (5.0- 8.5) $10^{-5}$ моль/дм ${ }^{3}$ и $\mathrm{pH} 5.6 \pm 0.5$, помещали диск бумажной отливки целлюлозсодержащей матрицы в виде квадрата со стороной 15 мм и массой $(0.0248 \pm 0.0050)$ г. Содержимое колбы перемешивали в течение 40 минут при комнатной температуре. После декантации отливку целлюлозсодержащей матрицы помещали на фильтровальную бумагу и сушили на воздухе.

Остаточную концентрацию формазана в растворе определяли фотометрическим методом по предварительно построенному графику зависимости оптической плотности от концентрации органического реагента.

Результаты анализа обрабатывались с вычислением среднего арифметического значения величины адсорбции для каждой исследуемой концентрации из трех выполненных экспериментов.

Кислотность водно-этанольных растворов формазанов контролировали на иономере АНИОН-4100 со стеклянным электродом.

Определение содержания карбоксильных групп целлюлозосодержащих матриц из шелухи риса (ОШР) и композиции из шелухи риса и соломы овса (КРС) выполнено методом потенциометрического титрования выделившейся уксусной кисло- 
ты после взаимодействия кислотных групп с ацетатом кальция [19]. Содержание карбоксильных групп составляет 0.495 и 0.401 ммоль/г для ОШР и КРС, соответственно.

Электронные спектры поглощения образцов измеряли на спектрофотометре UV-1800 фирмы Shimadzu (Япония).

Исследование поверхности полученных целлюлозосодержащих сорбентов проводили методом сканирующей (растровой) электронной микроскопии (CEM). Образцы исследовались без предварительной подготовки в режиме низкого вакуума на микроскопе (JSM-6390/LV, Япония) во вторичных и обратно-рассеянных электронах. Обработку изображений проводили программой ФемтоСкан.

\section{Обсуждение результатов}

В работе использовались твердофазные матрицы в виде бумажных отливок (дисков) двух типов, полученные на основе технической целлюлозы окислительноорганосольвентным способом из шелухи риса (ОШР) и композиции (КРС) из шелухи риса и соломы овса, выступающей в композиции в качестве армирующего материала (оптимальным оказалось соотношение (от общей массы композиции) - 50\% целлюлозы из шелухи риса и 50\% целлюлозы из соломы овса). Физико-химические показатели полученной технической целлюлозы из шелухи риса и соломы овса представлены в [5-7]. Так как целлюлоза из шелухи состоит из коротких волокон, то отливки из нее обладают низкими прочностными характеристиками. Однако, поскольку целлюлоза из рисовой шелухи содержит большое количество губковых волокон, которые после варки сохраняют свою первоначальную структуру и скреплены друг с другом, по своим впитывающим и сорбционным свойствам, а также по высокой способности к набуханию и водоудержанию целлюлоза, полученная из шелухи риса, превосходит целлюлозу из соломы.

Для модификации целлюлозосодержащей матрицы были выбраны гетарилформазаны (таблица 1), отличающиеся природой гетероциклического фрагмента и введенных при синтезе заместителей $\mathrm{R}_{1}, \mathrm{R}_{2}$ и образующие с ионами двухвалентных металлов глубокоокрашенные комплексные соединения с высоким контрастным цветовым переходом [16, 17$]$.

Иммобилизацию формазанов I-IX на матрицы ОШР и КРС проводили в статических условиях методом переменных концентраций [19] водно-этанольных растворов (10:1) формазанов при 293 К. На основании полученных зависимостей относительной скорости достижения сорбционного равновесия от длительности процесса установлено, что для всех концентраций оптимальным временем контакта является 40 минут, дальнейшее увеличение времени не ведет к изменению цветовых характеристик носителя. Характеристики формазанов I-IX и полученныX на их основе целлюлозосодержащих сорбентов 1-8 приведены в таблице 2.

Установлено, что характер изотерм адсорбции формазанов на ОШР и на матрицу КРС различен и зависит как от структуры реагента, так и состава твердофазных носителей (рис. 1-5). Так, изотермы сорбции формазанов I-IX на целлюлозосодержащие подложки ОШР из шелухи риса (рис. 1-3) относятся к изотермам L2-типа по классификации Джайлса [21]. Изотермы L-типа наблюдаются, когда взаимодействие между адсорбированными молекулами пренебрежимо мало, а энергия активации не зависит от степени заполнения поверхности, что свидетельствует о высоком сродстве сорбента к сорбату: степень удерживания формазанов I-III, V-IX на матрице ОШР составляет 90\%. 
Таблица 1. Гетарилформазаны для модификации целлюлозсодержащих матриц $\mathrm{Het}-\mathrm{NH}-\mathrm{N}=\left.\right|_{\mathrm{R}_{1}} ^{\mathrm{C}}-\mathrm{N}=\mathrm{N}-$

\begin{tabular}{|c|c|c|c|c|c|c|c|}
\hline $\begin{array}{c}\text { № } \\
\text { соед. }\end{array}$ & Het & $\mathrm{R}_{1}$ & $\mathrm{R}_{2}$ & $\begin{array}{c}\text { № } \\
\text { соед. }\end{array}$ & Het & $\mathrm{R}_{1}$ & $\mathrm{R}_{2}$ \\
\hline I & & $\mathrm{C}_{2} \mathrm{H}_{5}$ & $\mathrm{H}$ & VI & & $\mathrm{C}_{2} \mathrm{H}_{5}$ & $2-\mathrm{CH}_{3}$ \\
\hline II & & $\mathrm{C}_{2} \mathrm{H}_{5}$ & $2-\mathrm{CH}_{3}$ & VII & & $\mathrm{CH}_{3}$ & $\mathrm{H}$ \\
\hline III & & $\mathrm{C}_{2} \mathrm{H}_{5}$ & 4-COOH & VIII & & $\mathrm{CH}_{3}$ & $2-\mathrm{CH}_{3}$ \\
\hline IV & & $\mathrm{CH}\left(\mathrm{CH}_{3}\right)_{2}$ & $4-\mathrm{COOH}$ & IX & & $\mathrm{CH}_{3}$ & 4-COOH \\
\hline V & $\mathrm{CH}_{2} \mathrm{C}_{6}$ & $\mathrm{C}_{2} \mathrm{H}_{5}$ & $\mathrm{H}$ & & & & \\
\hline
\end{tabular}

Таблица 2. Физико-химические характеристики формазанов I-IX и целлюлозосодержащих сорбентов 1-8

\begin{tabular}{|c|c|c|c|c|c|c|c|c|}
\hline \multirow{2}{*}{$\begin{array}{l}\text { № } \\
\text { соед. }\end{array}$} & \multicolumn{2}{|c|}{$\begin{array}{c}\lambda_{\text {макс., }} \text { нм } \\
\text { (этанол : вода, } 10: 1)\end{array}$} & \multirow{2}{*}{$\begin{array}{c}\text { № } \\
\text { cop- } \\
\text { бен- } \\
\text { та }\end{array}$} & \multicolumn{2}{|c|}{$\begin{array}{c}\mathrm{a}_{\text {макс. }}, \\
\text { ММОЛЬ/КГ }\end{array}$} & \multirow[b]{2}{*}{ 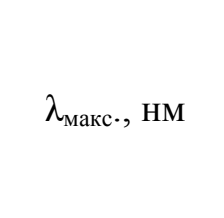 } & \multicolumn{2}{|c|}{$\mathrm{HA}: \mathrm{A}^{-}$} \\
\hline & $\begin{array}{c}\text { до иммо- } \\
\text { би- } \\
\text { лизации }\end{array}$ & $\begin{array}{c}\text { после } \\
\text { иммоби- } \\
\text { лизации }\end{array}$ & & ОШР & $\mathrm{K}$ & & ОШР & K \\
\hline I & 430 & $430,500-580$ & 1 & 1.21 & - & $430,500-580$ & $10: 2$ & - \\
\hline II & 435 & $435,500-580$ & 2 & 1.42 & - & $435,500-580$ & $9: 3$ & - \\
\hline III & 460 & $460,600-660$ & 3 & 1.52 & - & $460,600-660$ & $8: 4$ & - \\
\hline IV & 455 & $455,520-580$ & 4 & 0.33 & - & $455,520-580$ & $7: 5$ & - \\
\hline $\mathrm{V}$ & 460 & $460,560-580$ & 5 & 4.66 & 4.58 & $460,560-580$ & $10: 2$ & $9: 3$ \\
\hline VI & 460 & $460,560-580$ & 6 & 5.96 & 5.88 & $460,560-580$ & $9: 3$ & $8: 4$ \\
\hline VII & 357,378 & 378,500 & 7 & 5.60 & 5.11 & 380,500 & $10: 2$ & $9: 3$ \\
\hline VIII & 348,380 & $348,380,520-560$ & 8 & 7.46 & 7.41 & $385,520-560$ & $9: 3$ & $8: 4$ \\
\hline IX & 360,390 & $395 ; 510$ & 9 & 12.26 & 12.06 & $400 ; 510$ & $8: 4$ & $7: 5$ \\
\hline & $\begin{array}{c}1 \\
0.8 \\
0.6 \\
0.4 \\
0.2 \\
0 \\
0 \\
0\end{array}$ & 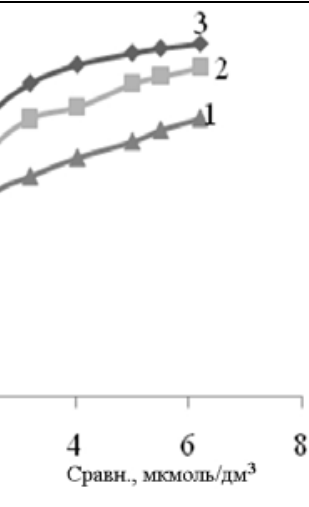 & & & 0 & $\begin{array}{c}10 \\
\text { Сравн., мкммо }\end{array}$ & 20 & \\
\hline
\end{tabular}

Рис. 1. Изотермы адсорбции бензтиазолилформазанов I-IV на матрице ОШР: 1- формазан I, 2 - формазан II, 3 - формазан III, 4 - формазан IV.
Рис. 2. Изотермы адсорбции бензилбензимидазолилформазанов V-VI на матрице ОШР: 1 - формазан V, 2 - формазан VI. 


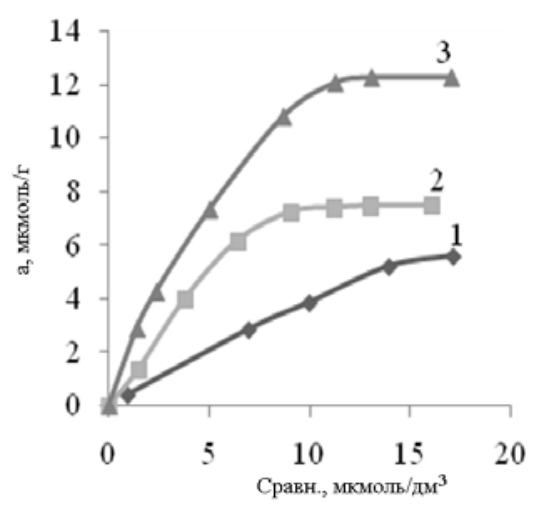

Рис. 3. Изотермы адсорбции дифенилпиримидинилформазанов VII-IX на матрице ОШР: 1 - формазан VII, 2 - формазан VIII, 3 - формазан IX.

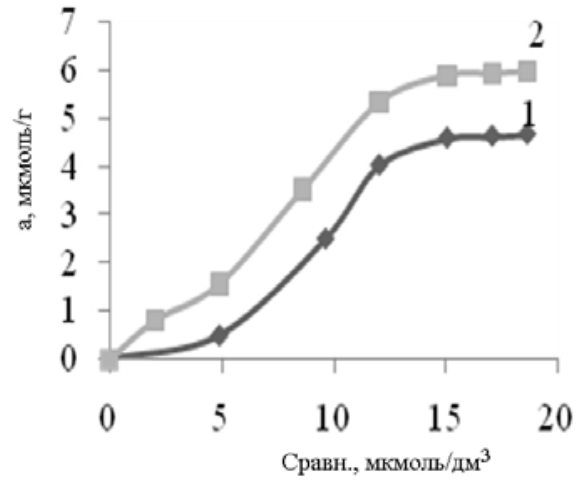

Рис. 4. Изотермы адсорбции бензилбензимидазолилформазанов V-VI на матрице КРС: 1 - формазан V, 2 - формазан VI.

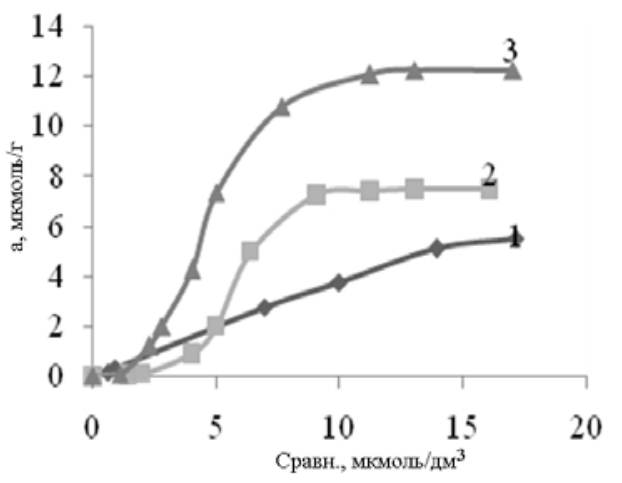

Рис. 5. Изотермы адсорбции дифенилпиримидинилформазанов VII-IX на матрице КРC: 1 - формазан VII, 2 - формазан VIII, 3 - формазан IX.

Отмечено, что количество закрепленных формазановых группировок $\left(\mathrm{a}_{\text {макс. }}\right.$ ) на ОШР увеличивается в ряду: бензтиазол- < бензилбензимидазолил- < дифенилпиримидинилформазанов (табл. 2). Наличие в орто-положении фенильного заместителя $\mathrm{R}_{2}=\mathrm{OCH}_{3}$ и nара-положении акцепторной карбоксигруппы $\mathrm{R}_{2}=\mathrm{COOH}$ способствует увеличению количества закрепленных группировок на матрице. Исключение составляет лишь сорбент 4, для которого количество закрепленных группировок 3изопропилформазана IV почти в 4.6 раза меньше, чем 3-этилпроизводного аналога III (табл. 2).

При изучении адсорбции формазанов на матрицу КРС из композиции шелухи риса и соломы овса установлено, что бензтиазолилсодержащие формазаны I-IV не удерживаются на ее поверхности (табл. 2), а сорбция формазанов V, VI, VIII, IX, в отличие от матрицы из ОШР, описывается изотермой S-типа (рис. 4-5), характерной для нехимических типов адсорбции, обусловленных образованием водородных или гидрофобных связей. Такие изотермы характерны для веществ, обладающих малым сродством к сорбенту: сила взаимодействия между адсорбируемыми молекулами больше силы взаимодействия между растворимым веществом и адсорбентом. Перегибы, возникающие на изотерме сорбции, очевидно, связаны с изменением ориентации молекул адсорбированного вещества или с образованием второго слоя адсорбированных молекул в виде агрегатов молекул формазана на поверхности носителя.

Общей тенденцией, выявленной при изучении иммобилизации на целлюлозосодержащие матрицы исследуемых формазанов I-IX является то, что окраска полученных модифицированных сорбентов 1-8 не совпадает с цветом раствора исходного реагента (табл. 2). В спектрах диффузного отражения модифицированных сорбентов 
1-8 наряду с интенсивной полосой основного максимума наблюдается поглощение, соответствующее поглощению ионизированной формы реагента, иммобилизованного на поверхность матрицы. Оказалось, что соотношение неионизированной формы

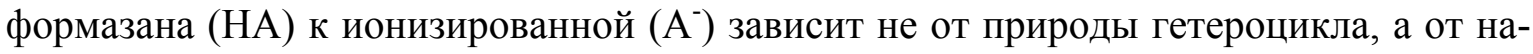
личия, характера и положения заместителя $\mathrm{R}_{2}$ в фенильном фрагменте формазановой цепи. Так, количество ионизированной формы изменяется в ряду: фенил-<орто-

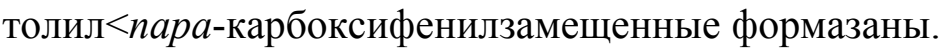

Кроме того состав самой целлюлозной матрицы также оказывает влияние на образование ионизированной формы формазанов. В процессе иммобилизации формазанов на матрицу из шелухи риса и соломы овса равновесие НА $\rightleftharpoons \mathrm{A}^{-}$смещается в сторону увеличения ионизированных молекул реагента, что сказывается на углублении окраски матрицы по сравнению с аналогичным твердофазным реагентом на подложке из рисовой шелухи (исключение составляет 1-фенил-3-метил-5-(4,6дифенилпиримидин-2-ил)формазан VII: характер изотерм адсорбции данного формазана на ОШР и КРС не меняется (рис. 3, 5)).

Синтезированные сорбенты 1-4 с иммобилизованными 5-(бензтиазол-2ил)формазанами и сорбенты 7-9, модифицированные 5-(4,6-дифенилпиримидин-2ил)формазанами, позволяют визуально детектировать наличие в воде ионов ртути(II) и меди(II) при концентрации не менее 1.0 мкг/см ${ }^{3}$. Однако изменения интенсивности окраски матрицы при увеличении концентрации токсикантов не наблюдается, следовательно, разработанные тест-формы успешно могут быть использованы только для экспресс-обнаружения ртути(II) в водных системах.

Методом сканирующей электронной микроскопии (СЭМ) в режиме вторичных электронов при различном увеличении в режиме естественной среды проведено исследование морфологии поверхности исходной матрицы ОШР и сорбента 9, модифицированного 1-(4-карбоксифенил)-3-метил-5-(4,6-дифенилпиримидинил)формазаном IX (рис. 6).
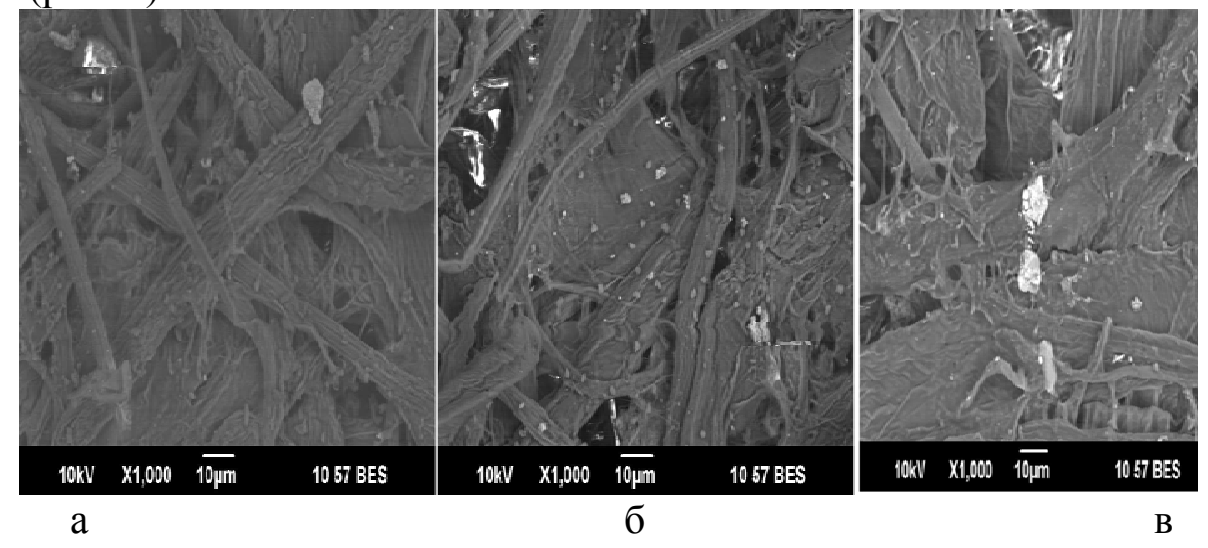

Рис. 6. Микрофотографии поверхности матрицы ОШР на основе технической целлюлозы из шелухи риса, полученные методом сканирующей электронной микроскопии при увеличении в 1000 раз: а) исходная матрица ОШР; б) сорбент 9;

в) после взаимодействия сорбента 9 с водным раствором ацетата ртути (II).

Исходная матрица на основе технической целлюлозы из ОШР содержит большое количество губковых волокон, которые скреплены друг с другом, напоминая «пазл» (рис. 6а). Иммобилизованный формазан IX на поверхности волокон ОШР виден в виде светлых частиц, как мелких (<1 мкм), так и крупных (до 3 мкм), расположенных неравномерно (рис. 6б). После контакта исследуемого сорбента 9 с раствором ацетата ртути(II) морфология поверхности ОШР не изменилась, однако наряду с частицами формазана появились частицы размером $\sim 5$ мкм. Очевидно, обра- 
зовавшиеся внутрикомплексные соединения ртути(II) образуют скопления или агломераты (рис. 6в).

Для бензилбензимидазолилсодержащих сорбентов 5-6 наблюдается проявление аналитического сигнала только при взаимодействии с ионами $\mathrm{Cu}(\mathrm{II})$, причем формирование комплексных соединений сине-фиолетовой гаммы $\left(\lambda_{\text {макс }}=610 \mathrm{Hм}\right)$ происходит в течение 30 минут. Увеличение интенсивности окраски полученного внутрикомплексные соединения пропорционально содержания ионов меди(II) в диапазонах 0.1 до 1.3 мг/дм ${ }^{3}$, что позволило разработать одноцветную цветовую шкалу для тест-определения ионов данного металла в водном растворе.

Обработку окрашенных форм матриц проводили с помощью сканера и компьютерной программы «Photoshop» [22], позволяющей построить цветовые шкалы, где каждому значению концентрации меди соответствовали цифровые значения цвета RGB. Определение координаты цвета в системе RGB позволили выявить, что зависимость координаты $\mathrm{R}$ от концентрации меди имеет линейный характер в диапазоне от 0.1 до 1.3 мг/дм ${ }^{3}$ (рис. 7$)$.

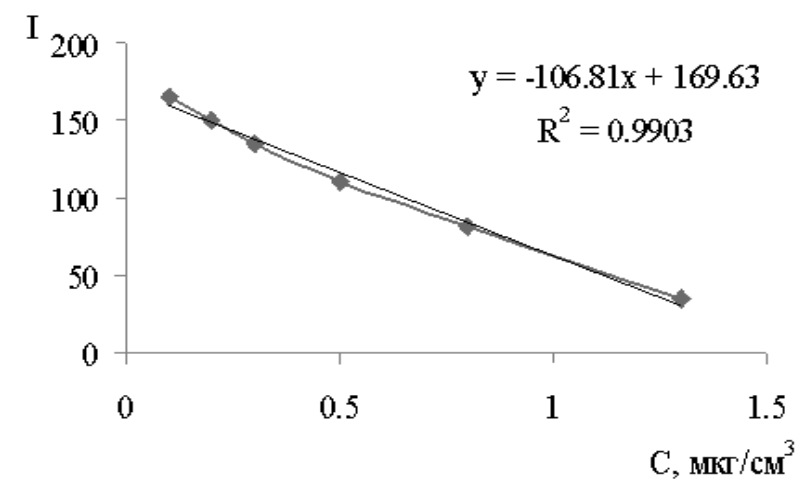

Рис. 7. Зависимость яркости R-составляющей окраски комплекса меди на сорбенте 6 от концентрации ионов меди(II) в водном растворе

Правильность методики определяли методами инверсионной вольтамперометрии и «введено-найдено». Результаты определения ионов $\mathrm{Cu}(\mathrm{II})$, свидетельствуют об удовлетворительной правильности и воспроизводимости предложенных методик.

\section{Заключение}

Таким образом, установлено, что характер изотерм адсорбции гетарилформазанов на твердофазные целлюлозные матрицы, полученные окислительноорганосольвентным способом из шелухи риса (ОШР) и композиции (КРС) из шелухи риса и соломы овса, различен и зависит как от структуры иммобилизованного реагента, так и состава самих твердофазных носителей. Определены спектральные и физико-химические характеристики синтезированных модифицированных сорбентов и показано, что их окраска определяется соотношением неионизированной и ионизированной форм соответствующего формазана. Найдены перспективные тестформы для обнаружения и определения ионов ртути(II) и меди(II).

\section{Список литературы}

1. Боголицын К.Г. // Российский 2. Сергиенко В.И., Земнухова Л.А., Егохимический журнал. 2004. Т.48. № 6. С. 105- ров А.Г., Шкорина Е.Д. и др. // Российский 123. 
химический журнал.2004. Т. 48. № 3. С. 116124.

3. Онищенко Д.В., Рева В.П., Чаков В.В. // Экология и промышленность России. 2013. № 1. C. 39-43.

4. Фогель А.А., Сомин В.А., Комарова Л.Ф. // Химия в интересах устойчивого развития. 2011. Т.19. С.461-465.

5. Вураско А.В., Дрикер Б.Н., Мозырева Е.А., Земнухова Л.А. и др. // Химия растительного сырья. 2006. № 4. С. 5-10.

6. Вураско А.В., Минакова А.Р., Дрикер Б.Н. // Химия растительного сырья. 2010. № 1. C. $35-40$.

7. Вураско А.В., Дрикер Б.Н., Мертин Э.В., Сиваков В.П. и др. // Вестник Казанского технологического университета. 2012. Вып. 6. С. 128-132.

8. Золотов Ю.А. // Российский химический журнал. 2005. Т. 49. № 2. С. 6-10.

9. Майстренко В.Н., Хамитов Р.3., Будников Г.К. Эколого-аналитический мониторинг суперэкотоксикантов. М. Химия. 1996. $319 \mathrm{c}$.

10. Майстренко В.Н., Клюев Н.А. Эколого-аналитический мониторинг стойких органических загрязнителей. М. БИНОМ. Лаборатория знаний. 2004. $323 \mathrm{c}$.

11. Золотов Ю.А. // Вестник РАН. 1997. T.67. № 6. C. 508-513.

12. Золотов Ю.А., Иванов В.М., Амелин В.Г. Химические тест-методы анализа. М. Едиториал УРСС. 2002. 304 с.

\section{References}

1. Bogolicyn K.G., Rossijskij himicheskij zhurnal, 2004, Vol. 48, No 6, pp. 105-123.

2. Sergienko V.I., Zemnuhova L.A., Egorov A.G., Shkorina E.D. et al., Rossijskij himicheskij zhurnal, 2004, Vol. 48, No 3, pp. 116124.

3. Onishhenko D.V., Reva V.P., Chakov V.V., Jekologija i promyshlennost' Rossii, 2013, No 1, pp. 39-43.

4. Fogel' A.A., Somin V.A., Komarova L.F., Himija $v$ interesah ustojchivogo razvitija, 2011, Vol. 19, pp. 461-465.

5. Vurasko A.V., Driker B.N., Mozyreva E.A., Zemnuhova L.A. et al., Himija rastitel'nogo syr'ja, 2006, No 4, pp. 5-10.

6. Vurasko A.V., Minakova A.R., Driker B.N., Himija rastitel'nogo syr'ja, 2010, No 1, pp. 35-40.
13. Островская В.М., Запорожец О.А., Будников Г.К., Чернавская Н.М. Вода. Индикаторные системы. М. ВИНИТИ РАН. 2002. $265 \mathrm{c}$.

14. Амелин В.Г. // Журнал аналитической химии. 2008. Т.63. №3. С. 327-329.

15. Саввин С.Б., Дедкова В.П., Швоева О.П. // Успехи химии. 2000. Т.69. № 3. С. 203217.

16. Бузыкин Б.И., Липунова Г.Н., Сысоева Л.П., Русинова Л.И. Химия формазанов. М. Наука. 1992. $376 \mathrm{c.}$

17. Прогресс в химии формазанов: синтезсвойства-применение / под ред. И.Н. Липунова, Г.И. Сигейкига. М. ООО Издательство «Научный мир», Научный мир. 2009. 296 с.

18. Липунов И.Н., Сигейкин Г.И., Первова И.Г., Липунова Г.Н. // Российский химический журнал. 2006. Т. 50. № 5. С. 64-69.

19. Данченко Н.Н., Гармаш А.В., Перминова И.В. // Вестник Московского университета. Сер. 2. Химия. 1999. Т. 40. № 3. С. 183-187.

20. Полянский Н. Г., Горбунов В.Г., Полянская Н.Л. Методы исследования ионитов. М. Химия. 1976. 208 с.

21. Адсорбция из растворов на поверхности твердых тел / Под ред. Г. Парфита, К. Рочестера. Пер. с англ. Б.Н. Тарасевича. М. Мир. 1986. 488 c.

22. Климин О.А., Черкасова Т.А., Лейкин Ю.А. // Сорбиионные и хроматографические проиессы. 2012. Т. 12. № 5. С. 746-751.

7. Vurasko A.V., Driker B.N., Mertin Je.V., Sivakov V.P. et al., Vestnik Kazanskogo tehnologicheskogo universiteta, 2012, No 6, pp. 128132.

8. Zolotov Ju.A., Rossijskij himicheskij zhurnal, 2005, Vol. 49, No 2, pp. 6-10.

9. Majstrenko V.N., Hamitov R.Z., Budnikov G.K. Jekologo-analiticheskij monitoring superjekotoksikantov. M., Himija, 1996, 319 p.

10.Majstrenko V.N., Kljuev N.A. Jekologoanaliticheskij monitoring stojkih organicheskih zagrjaznitelej. M., BINOM, Laboratorija znanij, $2004,323 \mathrm{p}$.

11.Zolotov Ju.A., Vestnik RAN, 1997, Vol. 67, No 6, pp. 508-513.

12.Zolotov Ju.A., Ivanov V.M., Amelin V.G. Himicheskie test-metody analiza. M., Editorial URSS, 2002, $304 \mathrm{p}$. 
13.Ostrovskaja V.M., Zaporozhec O.A., Budnikov G.K., Chernavskaja N.M. Voda. Indikatornye sistemy. M., VINITI RAN, 2002, 265 p.

14.Amelin V.G., Zhurnal analiticheskoj himii, 2008, Vol. 63, No 3, pp. 327-329.

15.Savvin S.B., Dedkova V.P., Shvoeva O.P., Uspehi himii, 2000, Vol. 69, No. 3, pp. 203-217.

16.Buzykin B.I., Lipunova G.N., Sysoeva L.P., Rusinova L.I. Himija formazanov. M., Nauka, 1992, 376 p.

17.Progress $\mathrm{v}$ himii formazanov: sintezsvojstva-primenenie / pod red. I.N. Lipunova, G.I. Sigejkiga. M., OOO Izdatel'stvo «Nauchnyj mir», Nauchnyj mir, 2009, 296 p.

Маслакова Татьяна Ивановна - к.Х.н., доцент, кафедра физико-химической технологии защиты биосферы, Институт химической переработки растительного сырья и промышленной экологии, Уральский государственный лесотехнический университет, Екатеринбург

Первова Инна Геннадьевна - д.х.н., заведующий кафедрой, кафедра физико-химической технологии защиты биосферы, Институт химической переработки растительного сырья и промышленной экологии, Уральский государственный лесотехнический университет, Екатеринбург

Желновач Анастасия Валерьевна - аспирант, кафедра физико-химической технологии защиты биосферы , Институт химической переработки растительного сырья и промышленной экологии, Уральский государственный лесотехнический университет, Екатеринбург

Маслаков Павел Александрович - аспирант, кафедра физико-химической технологии защиты биосферы, Институт химической переработки растительного сырья и промышленной экологии, Уральский государственный лесотехнический университет, Екатеринбург

Симонова Елена Игоревна - ассистент, кафедра технологий целлюлозно-бумажного производства и переработки полимеров, Институт химической переработки растительного сырья и промышленной экологии, Уральский государственный лесотехнический университет, Екатеринбург

Вураско Алеся Валерьевна - д.т.н., заведующий кафедрой, кафедра технологий целлюлознобумажного производства и переработки полимеров, Институт химической переработки растительного сырья и промышленной экологии, Уральский государственный лесотехнический университет, Екатеринбург
18.Lipunov I.N., Sigejkin G.I., Pervova I.G., Lipunova G.N., Rossijskij himicheskij zhurnal, 2006, Vol. 50, No 5, pp. 64-69.

19.Danchenko N.N., Garmash A.V., Perminova I.V., Vestnik Moskovskogo universiteta. Ser. 2. Himija, 1999, Vol. 40, No 3, pp. 183-187.

20.Poljanskij N. G., Gorbunov V.G., Poljanskaja N.L. Metody issledovanija ionitov. M., Himija, 1976, 208 p.

21.Adsorbcija iz rastvorov na poverhnosti tverdyh tel / Pod red. G. Parfita, K. Rochestera. Per. s angl. B.N. Tarasevicha. M., Mir, 1986, $488 \mathrm{p}$.

22.Klimin O.A., Cherkasova T.A., Lejkin Ju.A., Sorbtsionnye $i$ khromatograficheskie protsessy, 2012, Vol. 12, No 5, pp. 746-751.

Maslakova Tatiana I. - Associate professor, Department of physical and chemical technologies in environmental engineering, Institute of Plant-Based Chemistry and Industrial Ecology, Ural State Forest Engineering university, Ekaterinburg, Russia

Pervova Inna G. - Professor of Chemistry, Head of the Department of physical and chemical technologies in environmental engineering, Institute of Plant-Based Chemistry and Industrial Ecology, Ural State Forest Engineering university, Ekaterinburg, Russia

Zhelnovatch Anastasia V. - PhD student, Department of physical and chemical technologies in environmental engineering, Institute of Plant-Based Chemistry and Industrial Ecology, Ural State Forest Engineering university, Ekaterinburg, Russia

Maslakov Pavel A. - PhD student, Department of physical and chemical technologies in environmental engineering, Institute of Plant-Based Chemistry and Industrial Ecology, Ural State Forest Engineering university, Ekaterinburg, Russia

Simonova Elena I. - Assistant, Department of pulp, paper and polymer technology, Institute of Plant-Based Chemistry and Industrial Ecology, Ural State Forest Engineering university, Ekaterinburg, Russia

Vurasko Alesia V. - Professor of Engineering, Head of Department, Department of pulp, paper and polymer technology, Institute of Plant-Based Chemistry and Industrial Ecology, Ural State Forest Engineering university, Ekaterinburg, Russia 